\title{
DIÁLOGOS SOBRE ESCOLA E DIFERENÇA: UMA PERSPECTIVA INTERSECCIONAL SOBRE O COTIDIANO ESCOLAR
}

Daniel Vieira Silva ${ }^{\mathrm{i}}$

\begin{abstract}
RESUMO
O presente trabalho pretende pensar os limites e possibilidades da escola no combate as violências (re)produzidas a partir de noções de diferença. Em meio a violências e resistências, o espaço escolar é colocado como lugar onde a teia do poder cria embaraços e caminhos. Utilizo como local de partida olhares trazidos por professoras que foram alunas do curso Gênero e Diversidade na Escola (GDE/UFRJ - 2014), levantando questões que desejam desafiar os olhares dicotômicos, que hora colocam a escola como espaço de manutenção e reprodução de opressões, hora como espaço de superação dos preconceitos e de possibilidade de construção de uma sociedade mais justa. Proponho que a escola seja tudo isso, em relações que se mostram complexas e contraditórias. Partimos dos relatos dessas professoras para analisar as relações de gênero e sexualidade, em diálogo com conceitos outros que também se debatem sob o guarda chuva da diversidade, tais como raça, classe e local de moradia, buscando compreender de que formas se articulam produzindo formas diversas de exclusão, marginalização, mas também de possibilidades e agências.
\end{abstract}

Palavras-chave: educação, diversidade, gênero, sexualidade, opressão

\section{ABSTRACT}

The present work intends to think the limits and possibilities of the school in the fight against the violence (re) produced from notions of difference. In the midst of violence and resistance, school space is placed as a place where the web of power creates embarrassments and pathways. I use as a starting point the looks brought by teachers who were students of the course Gender and Diversity in the School (GDE / UFRJ - 2014), raising questions that wish to challenge dichotomous looks, which place the school as a space for the maintenance and reproduction of oppressions, and also as a space for overcoming prejudices and the possibility of building a more just society. I propose that the school be all this, in relationships that are complex and contradictory. We start from the reports of these teachers to analyze gender relations and sexuality, in dialogue with other concepts that also debate under the umbrella of diversity, such as race, class and place of dwelling, trying to understand what forms are articulated producing different forms exclusion, marginalization, but also possibilities and agencies.

Keywords: education, diversity, gender, sexuality, oppression.

\section{INTRODUÇÃO}

Neste artigo, utilizo a experiência do curso GDE realizada em 2014, pela Universidade Federal do Rio de Janeiro (UFRJ) para pensar os desafios e possibilidades que se apresentam no cotidiano escolar. O referido curso foi construído e direcionado a profissionais da educação, especialmente docentes da escola pública. O objetivo principal era a construção de novas práticas pedagógicas que pudessem lidar com as violências ligadas à gênero, raça e sexualidade. 
Utilizarei a experiência específica da turma do município de Duque de Caxias, no Rio de Janeiro, em 2014. A partir das aulas e discussões, nos questionamos: de que maneiras o trabalho pedagógico e as estratégias didáticas podem se tornar dispositivos potentes na desconstrução dos padrões de gênero hegemônicos, da heteronormatividade e do eurocentrismo racial enquanto formas de entender o mundo?

Em nosso primeiro encontro, pedimos as/aos cursistas que escrevessem e compartilhassem com as demais pessoas, uma situação que tenha sido motivadora para que buscassem uma formação continuada nessas temáticas. O que despertou seu interesse? Por que considera importante estudar sobre isso? Por que participar do curso pode contribuir com sua prática profissional? Essas foram algumas perguntas lançadas, e cada participante deveria recordar alguma situação que tenha ocorrido em seu espaço de trabalho, consigo ou com outra pessoa, estudante ou profissional, que pudesse ilustrar suas respostas para as perguntas. Chamamos a essa dinâmica de "problema cabeludo". Decidi trazer tais falas como elementos disparadores e representativos do cotidiano das/os professoras/es que participaram do curso, assim como para disparar reflexões. As falas dessas/es professoras/es representam situações por vezes de extrema violência, mas que de alguma forma se aproximam de tantas experiências que vivemos cotidianamente. São representativas daquilo que nos choca, mas que faz parte da experiência escolar. Foram essas situações que me fizeram desejar pensar mais sobre isso, e assim elas estão no texto como forma de relacionar as análises teóricas com exemplos de nossa vivência, seja como estudantes e/ou docentes. Ainda que essas falas sejam exemplos escancarados de violência, sem dúvida podemos relaciona-las a outras situações, menos evidentes, mais corriqueiras, mas que estão também entrelaçadas nessas construções naturalizadas.

Inspirado por bell hooks (2013), espero que a potência desses relatos, aliada a reflexão e questionamento, possa nos motivar a produzir uma educação que rompa com os mecanismos de violência, exclusão e desigualdade. De acordo com as palavras da autora, em referência a Paulo Freire, uma educação como prática de liberdade. Convido a quem lê, principalmente, a partilhar e confessar. A autora nos diz que "quando a educação é a prática da liberdade, os alunos não são os únicos a serem chamados a partilhar, confessar" (p. 35). As nossas experiências também são extremamente importantes, e resgatar memórias de nosso tempo de estudante e também posturas e práticas atuais é uma metodologia muito interessante para se pensar os conceitos como gênero, sexualidade, raça e classe. Esses conceitos só fazem sentido quando podem ser exemplificados a partir das vivencias dos sujeitos. Não tenhamos medo, inclusive, de reconhecer nas nossas práticas pedagógicas situações parecidas com as relatadas. Nossa experiência foi/é construída 
com base em normativas, e reproduzi-las é o caminho mais lógico. Em uma sociedade racista, não ser racista é um exercício. Em uma sociedade homofóbica, não ser homofóbico/a é um esforço. Ou seja, as opressões raciais, de gênero e sexualidade nos atravessam, e estamos todas/os em uma teia que hora nos coloca na posição oprimida, hora na de opressão, e em muitos casos nas duas ao mesmo tempo.

\section{2 "No início do ano letivo a turma do $6^{\circ}$ ano rejeitou um professor por ele ser homossexual"}

A fala que inicia esse subcapítulo foi dita por uma professora da rede municipal de Nova Iguaçu/RJ, ao falar da chegada de um professor homossexual na escola em que trabalha. A professora também demarcou que a rejeição não foi somente por parte das/os estudantes, mas também do corpo docente da instituição. A orientação sexual tornou-se um fator que atravancou o trabalho do professor, e gerou desconforto de forma geral na escola.

Torna-se necessário refletir sobre a sexualidade e a experiência dos sujeitos que escapam da heteronormatividade. $\mathrm{O}$ relato da professora traz à tona o quanto todos os corpos são colocados em vigilância. Na escola, não somente as/os estudantes são regulados a todo instante, como também as/os profissionais que ali atuam.

Enquanto professor do primeiro segmento do ensino fundamental, atuo numa etapa de ensino em que a esmagadora maioria é composta de mulheres. É muito raro ver um homem atuando com crianças pequenas. Buscando em minhas memórias, recordo que ao me apresentar na escola, nem sequer me foi oferecida a turma de ensino infantil, que estava sem professor/a. Foi suposto que eu não iria querer trabalhar com essa faixa etária, ou não queriam que eu atuasse com crianças tão novas. Além disso, a todo instante a minha presença nesse espaço causa estranhamento, pois não se espera que um homem venha a se interessar por uma profissão construída com base nas normativas de femilinidade, ligada ao cuidado. As mulheres que atuam na mesma etapa da educação básica, também estão sob constante vigilância. Não foram poucos os relatos que ouvi sobre cobranças em relação a aparência e comportamento dessas mulheres. Roupas, maquiagem, forma de falar, de andar e de tratar as/os estudantes. São todos exemplos de como as construções de gênero tornam-se modos obrigatórios de ser, tanto em relação a homens e mulheres. Porém, é importante demarcar que quando falamos de representações, vivencias, exigências ou imposições de gênero, precisamos abandonar a concepção de masculinidade e feminilidade única, pois mesmo que existam certas compreensões clássicas do que é ser homem ou mulher, também existem muitos outros atravessamentos que regulam essas experiências. Por exemplo, no espaço escolar, assim como em outros espaços, a figura de uma mulher deve ser 
feminina, no entanto essa feminilidade exigida de uma mulher professora não é a mesma que outras mulheres que atuam em outras profissões. A feminilidade que a professora deve apresentar deve demonstrar que ela é feminina, que é cuidadosa com sua aparência, mas não deve "abusar" da feminilidade a ponto de ser sensual. A vigilância em relação a roupa, a maquiagem, a forma de falar, de andar, de se relacionar com responsáveis e com as crianças, todos esses elementos configuram uma feminilidade muito específica, que podemos chamar de feminilidade docente.

\section{3 "Ele não pode ser o orador da turma porque é muito plumas e paetês"}

Esta fala indica a rejeição de uma professora do ensino médio da indicação de um aluno que seria orador da formatura da turma. A professora que relatou esse fato disse que essa fala foi proferida em uma reunião de docentes, e não encontrou resistência no grupo. Ela percebeu certo incômodo, inclusive o próprio, porém não houveram manifestações contra.

Todos os meninos e meninas estudantes também são atravessados pelas exigências relacionadas a gênero. Essas exigências não partem somente das/os profissionais, mas também delas e deles. Faz parte do relato de muita/os docentes as cobranças que as crianças fazem umas com as outras sobre seus comportamentos e gostos. Coisas simples como escolher a cor de um lápis de cor ou um brinquedo tornam-se conversas interessantes entre elas.

$\mathrm{Na}$ pesquisa que desenvolvo atualmente no mestrado em educação, entrevisto algumas professoras que foram cursistas do GDE/UFRJ 2014. Todas as professoras, durante as entrevistas, apontaram situações que exemplificam as situações cotidianas que (re)produzem lógicas normativas de gênero. No relato delas, surgem várias situações em que as crianças cobram uma das outras o comportamento esperado para o gênero ao qual são reconhecidas. No entanto, também estão presentes no relato delas as estratégias encontradas para lidar com essas situações. Ressalto uma experiência de Maria ${ }^{i i}$, que contou:

Eu ganhei um monte de boneca e um monte de carrinho. Eu pensei: vou apresentar pra eles. Peguei as bonecas de um lado e os carrinhos de outro. As meninas doidas, porque tinha uma Barbie. Então mostrei o carrinho, e perguntei quem podia brincar com o carrinho. Todo mundo respondeu: os meninos. Eu disse: "ih, e agora? Eu tenho um carro! Vou ter que vender meu carro! Eu sou menina, então não posso andar de carro. Só os meninos podem. "Não tia, você pode, você é grande". Eu disse: não, eu posso porque todo mundo pode. E se eu posso ter um carro, as meninas podem brincar de carro, elas vão fingir que estão no carro delas, e quando elas crescerem vão ter um carro igual ao que a tia tem. Pronto. As meninas brincam de carro agora. Entendeu?

No entanto, Maria também traz relatos da vigilância que ela, enquanto professora que discute essas temáticas por um viés contra hegemônico, enfrenta na escola. Ao relatar outra 
situação ligada diretamente a comportamentos esperados para cada gênero, ela fala da reação de outra professora da escola:

E eu lembro que tinha uma coisa: toda vez que era hora de brincar, na minha sala tinha uma fantasia de homem aranha e uma fantasia de baiana. Toda vez que era hora de brincar ele ficava ansioso, preparado, porque quando eu falava "pode brincar", ele corria e colocava a baiana na hora. E tinha uma professora do lado que ouvia, porque nossa sala era colada, ela ouvia tudo. Aí nas primeiras vezes que o Adria, o nome do menino era Adria. Nas primeiras vezes que o Adria pegou a baiana, os outros meninos falaram né "roupa de mulherzinha". Aí eu parei a aula e falei: é uma fantasia como outra qualquer, se ele se sente bem ele pode usar. Ela (a outra professora) saiu lá da sala dela, veio na minha porta e falou comigo: eu to vendo hein, você ensinando o garoto a usar roupa de mulher. Eu falei pra ela assim: eu não to ensinando ele a usar roupa de mulher não, eu to ensinando ele a usar a roupa que ele quiser, porque a vida dele e ninguém tem nada com isso, Aí ela foi e deu uma risadinha e saiu.

Durante minha trajetória como professor, minha sala de aula é constantemente visitada por outras profissionais da escola durante minhas aulas. Várias vezes por dia a orientadora pedagógica entrava, algumas vezes a orientadora educacional e por vezes as diretoras. Algumas vezes essa chegada era para dar bom dia para as turmas, algumas vezes era para perguntar algo simples que poderia aguardar o término da aula. Só me dei conta que essas visitas não eram comuns quando compartilhei isso com outras professoras, e ouvi delas que isso não acontecia com elas. Essa vigilância pode ocorrer por vários motivos, mas sem dúvida existe uma curiosidade ou preocupação com o trabalho que desenvolvo em sala de aula.

Porém, no meu caso e no de muitas outras pessoas, existe um outro fator que torna essa experiência mais difícil para mim e para as outras pessoas: eu sou classificado como afeminado. Ou seja, minha aparência e modo de ser não corresponde aos modelos de masculinidade hegemônicos, ou pelo menos não em sua maioria. O desconcerto das pessoas ao me ver nesse espaço também passa pelo fato de ser, na visão das pessoas, um homem visivelmente gay. Percebo isso pois tive a oportunidade, nas duas escolas em que atuei em Nova Iguaçu, de trabalhar com outros dois professores na mesma etapa de ensino. No entanto, os dois são declaradamente heterossexuais, e agem de modo que outras pessoas não questionam sua masculinidade e, consequentemente, sua heterossexualidade. Apesar da presença desses homens nesse espaço também causar desconforto, o costume a essa presença e sua inserção nesse grupo torna-se mais facilitada.

Maria traz as percepções dela sobre a chegada de um professor homossexual na escola em que trabalha, e as reações a essa chegada por parte do restante do corpo docente e também do corpo discente. Ela fala que atuava em uma turma de $4^{\circ}$ ano do ensino fundamental na época da chegada desse professor, e que um de seus alunos se recusou a participar das aulas de educação 
física, disciplina lecionada pelo professor recém-chegado. Mais uma vez, além de relatar a situação, Maria conta como buscou lidar com ela:

Um dia eu estava na sala, e era aula do professor, e um aluno estava sentado na sala no canto. Perguntei: o que você está fazendo aqui? Ele respondeu: ah não vou pra aula não. Disse: claro que você vai para a aula, é uma aula como outra qualquer. O aluno disse: não gosto de gente assim. Perguntei: gente assim como? Gente que usa guarda chuva? Porque o professor usava um guarda-chuva no sol, porque ele é muito branco. Gente que usa bermuda? $\mathrm{O}$ aluno insistiu: gente que fala assim. E eu continuei questionando o menino, conversei com o garoto, levei ele até a aula e apresentei ao professor. Falei a ele: olha, esse aqui é o professor Fábio, é o professor de educação física que vai trabalhar com vocês. Com o aluno meio que foi resolvido.

Essas experiências demonstram que as normativas de gênero, apesar de colocar todas as pessoas sob suas imposições, limitando a experiência dos sujeitos, é nas pessoas que demonstram alguma forma de não conformidade que as violências vão se tornar mais explícitas e diretas. E também é importante destacar que essas crianças, jovens ou adultas/os que de alguma forma estremecem as percepções binárias e/ou heteronormativas de gênero são reconhecidas como sujeitos LGBT’s, ainda que não o sejam. Ou seja, mesmo uma criança que não se relaciona afetiva e sexualmente com pessoas de forma a construir relacionamentos amorosos, ou uma pessoa adulta que nunca tenha expressado ser bi ou homossexual, ambas serão alvo de violências verbais, físicas, exclusões e marginalizações caso não venham a se comportar de maneira inteligível com seu gênero.

Percebemos, por exemplo, que um grande número de pessoas que hoje se reconhece como parte da população LGBT relata episódios de violência e marginalização na escola. Essa população enfrenta na escola um espaço extremamente hostil, que não somente permite, mas reforça e produz a discriminação e a aversão a pessoas LGBT's. Dizer isso não significa afirmar que pessoas heterossexuais e/ou cisgêneras ${ }^{\text {iii }}$ não tenham impacto dessas construções. Sem dúvida, ao tratar gênero enquanto categorias binárias masculinas ou femininas, e a heterossexualidade como única forma natural de relação afetiva e sexual, as experiências de todas as pessoas tornam-se limitadas, e produzem também violências na vida das pessoas que se enquadram nesses modelos.

A propósito, a experiência de violência por não adequação aos padrões de gênero também é compartilhada por pessoas heterossexuais e/ou cisgêneras. Ou seja, ao nomear os sujeitos que não se comportam de acordo com o gênero imposto e/ou manifestam afetos e desejos por pessoas do mesmo gênero como gays, lésbicas ou transexuais, a escola também estabelece uma forma de dupla violência: primeiro, ao restringir e classificar as experiências dos sujeitos com base em estereótipos, o que acontece com sujeitos hetero ou homossexuais, cis ou transexuais; segundo porque classifica todo comportamento indesejado como LGBT, carregando essa 
população de todo o estigma do que é anormal. No entanto, independente de como aquele sujeito se reconhece ou reconhecerá em relação a sua identidade de gênero e orientação sexual, todos os corpos estão sendo postos sob as mesmas regras. $\mathrm{O}$ fato de alguns corpos parecerem se encaixar nos moldes propostos não quer dizer que não haja regulações, restrições e violências também em relação a eles.

Guacira Lopes Louro (2004) resgata suas lembranças escolares e nos fala que a escola "deixou marcas expressivas em seu corpo e $a$ ensinou a usá-lo de determinada forma" (p.11). A autora resgata suas memórias para falar do corpo educado, das estratégias escolares de produção de um corpo civilizado. As construções de gênero atravessam a produção desse corpo civilizado, seja pela vestimenta, pela forma de falar, de agir. As exigências para esses itens são diferenciados para meninos e para meninas. Guacira não evidencia qualquer incorfomidade com o gênero ao qual foi designada: menina, mulher. Porém, sem dúvida, seu relato questiona bastante as noções do que é ser menina ou mulher. Em seu texto, ela destaca que essa produção do corpo civilizado atravessa não somente estudantes, mas todo o corpo de sujeitos que compõem a escola.

Recordo que em uma das escolas que trabalhei o tamanho do vestido de uma professora tornou-se motivo de preocupação para a equipe diretiva. A professora em questão foi chamada para uma conversa, onde foi sugerido que ela utilizasse roupas que cobrissem mais o corpo. No entanto, outras professoras ouviam comentários por não utilizarem maquiagem ou roupas que a deixassem mais femininas. As mesmas professoras ouviam elogios surpresos de aprovação quando apareciam mais femininas. As meninas, também desde muito novas, tem suas roupas e comportamentos muito regulados. O tamanho do short ou da saia, o uso da maquiagem e sua relação com os meninos é vigiada o tempo inteiro.

Por outro lado, em uma ocasião em que uma vendedora de produtos de beleza fez uma exposição de seus produtos na sala de professoras/es, quando eu insisti em participar e utilizar as bases e demais artefatos, fui olhado com olhar incrédulo por algumas, e ouvi muitas piadas e risadas. Eu fui o único professor a participar da exposição, apesar de não ser o único homem trabalhando na escola. A ausência dos homens nesse espaço também diz muito.

Sem dúvida, a experiência de quem não está dentro de uma leitura normativa de gênero será marcada por violências múltiplas, físicas, verbais, mentais, subjetivas. No entanto, é importante analisar os atravessamentos de gênero e sexualidade que são dispostos a todas/os, compreendermos os processos de naturalização que algumas identidades encontram, enquanto outras são encaradas como anormais. 


\section{"Além de pobre, é preto e gay. É um caso perdido"}

No contexto em que a fala que nomeia esse subtítulo foi proferida, uma professora havia se desentendido com um estudante. Quando questionada, após o ocorrido, se gostaria de conversar com o aluno, ela deu essa resposta.

Torna-se importante pensar em como alguns marcadores de diferença se articulam na fala dessa docente, mas não somente na dela. A todo instante, na experiência dos sujeitos, esses diferentes marcadores encontram-se imbricados um no outro. Todos os corpos possuem uma experiência racializada, genereificada, sexualizada.

Em nossa sociedade os conceitos de gênero e sexualidade se cruzam com outras identidades, colocando alguns destes grupos numa condição maior de vulnerabilidade. Ideologias como o racismo, sexismo, homofobia, transfobia se relacionam a todo tempo colocando alguns sujeitos num espaço de subordinação maior que outros.

Brah (2006), ao discutir diferença, se coloca contra a noção de "essencialismo". A autora elenca questões que precisam ser levadas em consideração para uma análise das interconexões entre racismo, classe, gênero, sexualidade ou qualquer outro marcador de "diferença". A autora destaca:

Acima de tudo, sublinho a importância de uma macro-análise que estude as inter-relações das várias formas de diferenciação social, empírica e historicamente, mas sem necessariamente derivar todas elas de uma só instância determinante". (BRAH, 2006, p. 331)

A autora demarca ainda que as estruturas de classe, racismo, gênero e sexualidade não devem ser encaradas como "variáveis independentes", pois "a opressão de cada uma está inscrita dentro da outra" (p. 351).

Destaco na análise de Brah a importância de encarar esses marcadores da diferença como produções que constroem tanto a posição de opressão como a de privilégio. A autora fala sobre a necessidade de teorizarmos sobre a "posição privilegiada" das mulheres brancas. Segundo Brah, a falta dessa teorização, quando centramos nossas análises na opressão, mantemos os processos de dominação invisíveis. Essa é uma crítica que considero fundamental, pois propõe uma análise de nossas ações no sentido de trazer esses temas para o contexto escolar.

Entendemos que a escola sempre priorizou um currículo baseado no eurocentrismo e na heteronormatividade, naturalizando as relações de raça, gênero e sexualidade. Desejamos questionar essas construções, e um caminho possível é justamente visibilizar os grupos que estão excluídos desse tipo de currículo. A problemática que surge é a de centrarmos nossas ações na 
visibilidade desses grupos, e não discutirmos as relações históricas e sociais que constroem processos de dominação. Como exemplo trago o recente debate sobre a inserção da história e cultura negra na escola. A luta de diversos segmentos do movimento negro no Brasil conseguiu alterar a Lei de Diretrizes e Bases da Educação Nacional (LDBEN 9394/96), a partir da Lei 10.639, que institucionaliza o ensino da história e cultura negra no currículo escolar. Tal conquista é extremamente importante, como forma de questionarmos o eurocentrismo em que se baseia nosso conhecimento. Porém, é necessário pensarmos não somente na construção do sujeito negro, e nas relações de opressão sofrida por esse grupo, mas também retirar a categoria "branco" da posição naturalizada de dominação. Ou seja, é necessário também discutirmos as construções históricas de produção dessa identidade racial, ainda que sua posição privilegiada faça com que não a consideremos como uma identidade, para desconstruirmos os processos de dominação que permanecem invisíveis.

Torna-se, então, fundamental compreender a raça, enquanto conceito sociológico, e a construção do racialismo, que de acordo com Iolanda Oliveira (2016), partindo das reflexões de Torodov, é um processo histórico baseado na "na hierarquização da humanidade, a partir do referencial europeu" (p. 259). A autora destaca ainda que "esta maneira europeia de pensar a humanidade, embora sendo teoria, disseminou-se no mundo" oferecendo razão ao racismo. Iolanda ainda discorre em seu artigo sobre os impactos e repercussões do racismo na educação contemporânea, utilizando dados quantitativos que evidenciam a desigualdade racial, mas também qualitativos que nos oferecem a possibilidade de pensar como nossa prática docente compactua com essa realidade, mas também como pode ser agente de transformação.

Prosseguindo da reflexão de Iolanda, a autora classifica os mecanismos que perpetuam e reforçam o racismo no interior dos sistemas escolares em duas categorias: fatores espontâneos e não espontâneos. E assim os explica:

\footnotetext{
Os espontâneos decorrem da naturalização da situação de desigualdade dos negros, incorporada no imaginário dos profissionais da educação na sociedade e projetada nas suas atividades profissionais. Os não espontâneos, assim denominados para não utilizar a palavra intencionais a qual me parece não ser apropriada, são os que decorrem da não incorporação dos conteúdos sobre a diversidade racial nos projetos escolares e de ensino. Tais projetos deveriam ser elaborados a nível de escola para atender às particularidades do público atendido pela instituição e neste caso, a não incorporação seria intencional. (p. 279)
}

Torna-se especialmente interessante pensar na nossa responsabilidade enquanto docentes, e de como nossas práticas carregam sentidos e visões de mundo, mesmo que não nos demos conta, mesmo que sejam, na classificação da autora, espontâneos. No entanto, o fato de não serem consciente não faz com que as práticas racistas deixem de alcançar seu objetivo, que é a 
exclusão da população negra. Logo, precisamos questionar nossas práticas a partir das contribuições dos diversos conceitos que tratam da diversidade ou da diferença.

Scott (1989), em seu artigo "Gênero: uma categoria útil para análise histórica”, nos fala sobre como a categoria "gênero" passa a ser um importante elemento de questionamento dos saberes e histórias construídos.

Por que (e desde quando) as mulheres são invisíveis como sujeitos históricos, quando sabemos que elas participaram dos grandes e pequenos eventos da história humana? $\mathrm{O}$ gênero tem legitimado a emergência de carreiras profissionais? Para citar o título de um artigo recente da feminista francesa Luce Irigaray, o sujeito da ciência é sexuado? Qual é a relação entre a política do Estado e a descoberta do crime de homossexualidade? (SCOTT, 1989, p.28)

Qual é o impacto dessas perguntas naquilo que conhecemos como saber, ciência, história, ou qualquer outro conhecimento acumulado pela humanidade?

A exploração dessas perguntas fará emergir uma história que oferecerá novas perspectivas a velhas questões (como por exemplo, é imposto o poder político, qual é o impacto da guerra sobre a sociedade), redefinirá as antigas questões em termos novos (introduzindo, por exemplo, considerações sobre a família e a sexualidade no estudo da economia e da guerra), tornará as mulheres visíveis como participantes ativas e estabelecerá uma distância analítica entre a linguagem aparentemente fixada do passado e nossa própria terminologia. (SCOTT, 1989, p. 29)

Ou seja, a autora diz que o conceito de gênero pode e deve ser aplicado a qualquer que seja a área do conhecimento, visto que os saberes construídos por qualquer área foram formulados com base em uma concepção de gênero. A história, por exemplo, foi escrita e interpretada a partir de um viés patriarcal, onde a presença e atuação da mulher eram irrelevantes. Revisitar as histórias, buscando evidenciar as contribuições das mulheres sem dúvida irá afetar as formas com as quais as compreendemos. Assim, as categorias de gênero, assim como sexualidade e raça, precisam ser disparadoras de questionamento do currículo

Kimberlé Crenshaw (2002) sugere o uso do termo interseccionalidade em nossas análises. Através deste conceito percebemos como se constrói a dinâmica de subordinação de dois ou mais eixos identitários. Crenshaw nos chama atenção para dois problemas que surgem quando não damos a devida atenção para essas intersecções: ela os nomeia de "superinclusão" de "subinclusão". No termo superinclusão, demandas especificas de um subgrupo de mulheres são colocadas como problemas de todas, assim negando todo uma estrutura hierárquica à qual alguns grupos estão externamente impostos; já a subinclusão não deixa claro que alguns grupos de mulheres estão mais sujeitos a subordinação do que outros. Em resumo, Crenshaw explicita que nas abordagens subinclusivas da discriminação, a diferença torna invisível um conjunto de problemas; enquanto que, em abordagens superinclusivas, a própria diferença é invisível. (p. 
Percebemos que os marcadores de diferença se articulam nas experiências sociais. Peter Fry (1982) analisa a intersecção entre gênero, sexualidade e classe ao discutir sobre as diferentes classificações dadas aos homens homossexuais. As distinções estabelecidas para a "bicha" e o "homem" são exemplos de como os modelos de gênero são relacionados na análise desses sujeitos, assim como a classe torna-se um dispositivo de classificação. Em sua pesquisa na cidade de Belém, no estado do Pará, no ano de 1974, o autor demarca a compreensão social que classifica os sujeitos enquanto masculinos ou femininos, impondo a estes a binaridade de gênero, reproduzindo as relações de poder já tradicionais entre homens e mulheres. Dessa maneira, o "homem" era o sujeito masculino, e a "bicha" o feminino. Fry estabelece uma analogia entre essas relações e às relações heterossexuais no mesmo contexto social, "onde os papéis de gênero masculino e feminino são altamente segregados e hierarquizados." (p. 90).

O homem, nesse contexto, "poderia desempenhar comportamentos homossexuais se se restringisse à 'atividade"” (p. 94). Porém o autor traça um paralelo com uma nova classificação, surgida nas classes médias das cidades do Rio de Janeiro e São Paulo, onde surge a denominação do "entendido", que busca romper com a noção de que o homem que apenas penetra não é homossexual. Nessa classificação, "homem" seria o sujeito heterossexual, e todo sujeito que se relacionasse, quer de forma ativa ou passiva, com outro homem seria homossexual, ou "entendido". No entanto, a classificação de "bicha" não deixa de existir, porém é ligada às classes baixas, e "é menosprezada não só pela sua identidade um tanto espalhafatosa quanto pela sua posição de classe". (p. 95).

Através da pesquisa de Fry, percebemos uma relação muito próxima entre gênero, sexualidade e classe social, que se entrelaçam criando marcadores de diferença, que estão inseridos em paradigmas de desigualdade. Em outras pesquisas, como a de Piscitelli (2013), recortes de gênero, nacionalidade, raça e classe social se articulam, construindo experiências singulares de opressão. A autora, em sua pesquisa sobre o trânsito de brasileiras nos mercados transnacionais do sexo, evidencia as marcas de diferenciação vinculadas à brasilidade nos contextos transnacionais, e os significados atribuídos à etnicidade que diferem em distintos contextos migratórios. Nas experiências dessas mulheres, seja em relações de prostituição ou casamento, as marcas de raça, gênero, sexualidade e classe social adquirem diferentes significados, relacionando-se de forma a construir experiências que muitas vezes divergem das clássicas relações de dominação que conhecemos.

No processo de ressignificações de marcas de diferenciação, as entrevistadas recorrentemente acionam atributos que parecem remeter a versões "tradicionais" de feminilidade. A ativação dessas qualidades por mulheres posicionadas estruturalmente em lugares desiguais não significa, porém, aludir a posições de submissão. Ao 
contrário, elas utilizam desses atributos, que traduzem como marcas étnicas/nacionais, na construção de espaços de agência, principalmente no plano transnacional. (PISCITELLI, 2013, p. 230)

Através dessas experiências, é possível pensar no trabalho na/para diversidade de forma a relacionar os marcadores sociais de diferença com a construção de novas experiências de currículo e prática pedagógica. Mas, principalmente, a partir da reflexão interseccional, torna-se urgente analisar as práticas pedagógicas utilizadas pela escola em seu cotidiano, buscando compreender como (re) produz as desigualdades a partir dos marcadores de diferença.

\section{4 'Um aluno de 11 anos de idade foi obrigado a se despir na quadra esportiva da escola por que havia um boato de que ele era hermafrodita"}

A professora fez esse relato, explicando que esse aluno era muito afeminado, e que sua masculinidade era sempre colocada em cheque, a ponto das outras crianças duvidarem do órgão genital que ele teria.

A escola não inventou a hierarquia de gênero; sequer inventou o gênero, a sexualidade, a raça ou a classe. Porém, como instituição social, perpetua tais modelos, valorizando as diferenças que colocam a mulher em situação desprivilegiada. Enquanto instituição social, a escola acaba por reproduzir as construções que são difundidas na sociedade. Essa reprodução é especialmente perigosa quando compreendemos a escola como instituição responsável por propagar e difundir os conhecimentos científicos acumulados pela humanidade. A ciência que dá base aos conteúdos e temas trabalhados na escola legitima toda e qualquer informação ali transmitida. Dessa forma, mais do que apenas reproduzir a lógica hegemônica de gênero, a escola legitima a desigualdade vivenciada por mulheres. Os ensinamentos dessa instituição, assim como da ciência de forma geral, têm estatuto de verdade.

Ao nos debruçarmos sobre a escola para analisar os marcadores de diferença e as produções de subjetividade ali desenvolvidas, é preciso compreender que tais marcadores se relacionam a todo instante. Dessa forma, compreender a questão do gênero, por exemplo, exige uma relação com sexualidade, classe e raça. Ao relatar a situação de uma aluna negra que, em uma roda de dialogo confessa, frustrada, nunca ter sido convidada a participar das "brincadeiras de menina bonita", Lins e Oliveira (2012) nos apresentam como a questão da identidade estética está ligada às relações que irão se estabelecer dentro das relações de poder instituído no espaço escolar, e nos levam a entender que essa exclusão tem cor, condição social e local de moradia. Meninas negras que não se veem representadas nos murais espalhados pelos corredores escolares ou nas imagens dos livros didáticos nunca vão se enxergar como "meninas bonitas", ou dignas de 
serem convidadas a participar de atividades que sejam para "meninas bonitas". Gomes (2008) ressalta que:

Existe no interior do espaço escolar, determinada representação do que é ser negro, presente nos livros didáticos, nos discursos, nas relações pedagógicas, nos cartazes afixados nos murais da escola, nas relações professor/a aluno/a e dos alunos/a entre si. Na maioria das vezes, a questão racial existe na escola através da sua ausência e do seu silenciamento (GOMES, 2008, p. 187).

Dentro do espaço escolar, os marcadores de diferença também se reconfiguram, construindo novas formas de opressão. A própria divisão de turmas em meninos e meninas já é um exemplo de uma segregação que só faz sentido na escola. Em que outro espaço meninas e meninos são divididos por fileiras específicas? Tal divisão facilita a restrição de atividades direcionadas para cada gênero, que são também baseadas na produção histórica de gênero. Às meninas, os brinquedos que são voltados ao cuidado, vida doméstica, sensibilidade. Aos meninos, brinquedos e brincadeiras que estimulam a atividade física, a competitividade, a demonstração de força.

A vigilância da escola está sempre presente, buscando evitar que os corpos se desenvolvam fora do esperado. Todos os corpos são educados, porém em sentidos diferentes. As expectativas construídas para cada gênero estão em consonância com o que se espera de mulheres e homens. Essa vigilância se expressa nas roupas, que não devem ser curtas ou apertadas nas meninas, para que nenhuma expressão de sexualidade ocorra, mas também não podem ser muito largas, pois devem conservar sua feminilidade. Aos meninos, as roupas não podem ser curtas ou apertadas, para que não se pareçam com meninas. A escola também está atenta ao comportamento: meninas educadas, frágeis e delicadas; meninos fortes e espertos.

Meninas e meninos aprendem, antes de seu ingresso escolar, o que é ou não permitido para seu gênero. Não podemos responsabilizar unicamente a escola por essa construção binária de gênero. Assim como Louro:

\footnotetext{
Não pretendo atribuir à escola nem o poder nem a responsabilidade de explicar as identidades sociais, muito menos de determiná-las de forma definitiva. É preciso reconhecer, contudo, que suas proposições, suas imposições e proibições fazem sentido, têm "efeitos de verdade", constituem parte significativa das histórias pessoais (LOURO, 2001, p. 21).
}

Podemos perceber que a escola, geralmente, pouco faz para romper com essa dicotomia, acabando por naturalizá-la. Não apenas reafirma as construções sociais para cada gênero, como produz novas formas de divisão. Ao dividir meninos e meninas em diversas atividades, a escola está produzindo outras formas de divisão por gênero que só fazem sentido naquele espaço. Em qualquer outro lugar, as filas não são divididas por gênero, mas na escola sim. 


\section{"Somos todos diferentes" ou "Viva a diversidade"}

Frases como essas são comuns nas escolas, e na sociedade de forma geral. Exaltar a diferença como uma característica de todo e qualquer sujeito se tornou corriqueiro, e a esperança é que estas afirmações apaguem todas as relações de desigualdade.

Porém, é preciso aprofundar a reflexão sobre o que compreendemos como diferença, e os contextos em que estas se tornam marcadores que geram desigualdades e inscrevem os sujeitos em relações de subordinação ou privilégio. Afinal, para o sujeito LGBT, por exemplo, a afirmação de que "ser diferente é legal" não apaga as violências sofridas cotidianamente.

Como vimos, a escola não inventou os sistemas de classificação baseados em gênero, raça, sexualidade ou classe. Porém, como instituição social, legitima-os ao não questionar as relações sociais que as sustentam. Para além, a escola utiliza desses mesmos marcadores para também construir formas específicas de marginalização, e inventa novos dispositivos de exclusão dos sujeitos.

No entanto, o que o cenário atual nos mostra é que existe o desejo de superar esse paradigma, tornando a escola um espaço de valorização da diferença. É preciso pensar se estamos discutindo realmente as relações de poder que configuram as diferenças em posições de subordinação/privilégio. Considero que o conceito de interseccionalidade é necessário para a construção de novas práticas pedagógicas, que relacionem as opressões de forma a compreender as relações sociais e históricas que inscrevem os sujeitos em categorias desviantes da expectativa social.

Para esse objetivo, precisaremos considerar os marcadores de diferença, tais como raça, gênero, sexualidade e classe, como produções históricas e sociais interrelacionadas que perpassam todos os sujeitos. Precisamos desnaturalizar esses conceitos não somente nos sujeitos que se encontram em posição de subordinação, mas também evidenciar o caráter produzido das identidades a partir das quais somos classificadas/os.

Tais conceitos, ao serem tensionados por estudos e vivências, passam a ocupar outros espaços, como a produção de políticas públicas. Essas políticas poderão garantir direitos ou aprofundar a desigualdade, e por isso é importante perceber quais são as compreensões sobre gênero e sexualidade que permeiam as políticas públicas, especialmente em um tempo histórico que favorece o debate sobre a população LGBT, mas também está envolto em relações de conflito. Também é necessário refletir sobre as diversas compreensões sobre gênero e sexualidade que habitam o espaço escolar, através de docentes, estudantes, equipe pedagógica, responsáveis, etc. Não basta que a escola esteja disposta a falar sobre diversidade, é preciso que 
as pessoas que a constroem estejam dispostas a compreender que diversidade é essa, como ela se apresenta, quais são as relações de desigualdade que produz e, principalmente, reconhecer quem são os sujeitos que estão cobertos sob o manto da diferença. Assim, a escola passará, então, a utilizar a noção de diversidade para fazer emergir as discussões sobre LGBTfobia, misoginia, machismo, sexismo, racismo, e diversas outras formas de opressão, ao invés de enterra-las no discurso vazio e ineficaz da tolerância.

Logo, para buscarmos uma educação na e para a diversidade, precisamos repensar as próprias estruturas do que conhecemos como conhecimento escolar, e reconhecer que, mais do que ensinar conteúdos e saberes, a escola produz sujeitos, e os desdobramentos de suas práticas se manifestam na sociedade.

\section{REFERÊNCIAS}

BRAH, Avtar. Diferença, diversidade, diferenciação. In: Cadernos Pagu, Campinas, n. 26, 2006, p. 239-276.

CAETANO, Márcio. Movimentos curriculares e a construção da heteronormatividade. In: RODRIGUES, Alexsandro; BARRETO, Maria Aparecida Santos Corrêa (org.). Currículos, gêneros e sexualidades: experiências misturadas e compartilhadas. Vitória, ES : Edufes, 2013, p. 63-82.

CRESHAW, Kimberlé. Documento para o encontro de especialistas em aspectos da discriminação racial relativos ao gênero". Em Revista de Estudos Feministas, ano 10, 2002. Florianópolis: UFSC. pg: 171-188.

FRY, Peter. Da hierarquia à igualdade: a construção histórica da homossexualidade no Brasil”. In: Fry, P. Para inglês ver: identidade e política na cultura brasileira. Rio de Janeiro: Zahar, 1981.

GOMES, Nilma Lino. Sem perder a raiz: corpo e cabelo como símbolos da identidade negra. Belo Horizonte: Autêntica, 2008.

Hooks, bell. Ensinando a transgredir: a educação como prática da liberdade. Tradução de Marcelo Brandão de Cipola. - São Paulo: Editora WMF Martins Fontes, 2013.

JESUS, Jaqueline Gomes de. Transfobia e crimes de ódio: Assassinatos de pessoas transgênero como genocídio. In: MARANHÃO $\mathrm{F}^{\mathrm{o}}$, Eduardo Meinberg de Albuquerque (Org.). (In)Visibilidade Trans 2. História Agora, v.16, n 2, pp.101-123, 2013.

JESUS, Jaqueline Gomes de. Homofobia: identificar e prevenir. Rio de Janeiro: Metanoia Editora, 2015. 
LOURO, Guacira Lopes (Org.). O corpo educado. Belo Horizonte: Autêntica, 1999.

- Gênero, sexualidade e educação: uma perspectiva pós-estruturalista. Rio de Janeiro: Editora Vozes, 2012.

Pedagogias da sexualidade. In: (org.) O corpo educado: pedagogias da sexualidade. Belo Horizonte: Autêntica, 2000.

OLIVEIRA, Iolanda. A Construção Social e Histórica do Racismo e suas Repercussões na educação Contemporânea (p.257-281). In: Cadernos Penesb - FEUFF. (n.9) (dezembro 2007) Rio de Janeiro/ Niterói - EdUFF/ Quarter, 2007.

PISCITELLI, Adriana. "Interseccionalidades, categorias de articulação e experiências de migrantes brasileiras”.In: Sociedade e cultura, Goiânia, v. 11, n.2, 2008.

SCOTT, Joan. Gênero, uma categoria útil de análise histórica”. In: Educação e Realidade, 16(2). Porto Alegre, Faced, UFRGS, 1989.

VIVEROS, Mara. "La sexualización de la raza y la racialización del sexo en el contexto latinoamericano actual”. In Gloria Careaga (org.) La sexualidad frente a la sociedad. México, D.F., 2008.

\footnotetext{
i Graduação em Pedagogia pela Universidade do Estado do Rio de Janeiro. Mestrando do Programa de Pós Graduação em Educação, Cultura e Comunicação em Periferias Urbanas (PPGECC/UERJ). Docente da Rede Municipal de Educação de Nova Iguaçu/RJ. Docente e Coordenador da Educação de Jovens e Adultos da Escola Politécnica Joaquim Venancio da Silva (ESPJV/FIOCRUZ)

ii Nome fictício

iii Utilizo o termo cisgênero em oposição ao termo transgênero. Cisgênera é a pessoa que se reconhece de acordo com o gênero ao qual foi designado. No entanto, esses termos carregam uma série de críticas pertinentes por parte da academia e dos movimentos sociais. Ainda assim, prefiro utiliza-lo pois acredito ser importante também nomear a norma.
} 